\title{
Analysis of the Impact of Corruption in the Health System and Some Recommendations Concepts
}

Budiarsih Budiarsih ( $\sim$ buddyarsih@gmail.com )

17 August 1945 University, Surabaya - Indonesia

\section{Research}

Keywords: Corruption, System, Health, Recommendations

Posted Date: September 7th, 2021

DOI: https://doi.org/10.21203/rs.3.rs-861370/v1

License: (9) This work is licensed under a Creative Commons Attribution 4.0 International License. Read Full License 


\section{Abstract}

A country that has a good system will be able to provide good services to its people, but in practice the regulations and financing systems experience obstacles. One of the problems faced by a country is fraud which has the potential to become an act of corruption. Corruption by some individuals is very detrimental to the community as recipients of health services. The data shows the purpose of creating a health system that has a good vision and mission, but in practice, it creates misery for the community, especially the middle to a lower class. During the Covid-19 pandemic, corruption in the financing of the health system also increased. Based on the above background, the researcher will focus on the issue of how to analyze the impact of corruption in the Health System and how to conceptualize recommendations to overcome it. Juridical normative and sociological methods are used to study the problems found and at the same time analyzed in the health financing system. The results of the study found that the health financing system has a noble purpose for the benefit of society. However, in its implementation, there are many errors in the system that result in actions and have the potential to become acts of corruption that result in state losses. Recommendations are made to be implemented immediately so that crime stops and society is protected.

\section{Introduction}

The health financing system in the form of public health insurance aims to provide financial protection and health service facilities for the poor. Several research methods were carried out to see whether the system being run was functioning properly. (Biggeri, Nannini, and Putoto 2018) Political support and the commitment of the authorities are potential factors in achieving the goals set by the state in determining health policy. (Chemouni 2018)The provision of universal health insurance is recognized as the main goal as a form of global health care (Tshitangano \& Olaniyi, 2018) it requires the awareness of all parties to achieve universal health(Adedeji et al., 2017). In general, health care uses 3 combinations, namely increasing resources for health, collecting resources, and buying health services. All three have an important role in the success of the health system and are supported by information technology(Meessen, 2018). The health system is highly vulnerable to corruption because of the many factors that can be played in the provision of health services. (Vian and Crable 2016). In general, corruption is the abuse or involvement in the abuse of public or private positions, satisfaction, or authority to benefit oneself, groups, organizations, or other people close to oneself. Where the possible benefits can be in the form of money, material, or non-material(Gaitonde et al., 2016). Corruption studies must be carried out in a holistic and multidisciplinary manner because acts of corruption in the health system cover various aspects. After all, corruption in the health sector is a systemic problem so that building a sustainable system must be a priority involving the health, economy, and law sectors for the benefit of the wider community. (Deliversky 2016; Lu, Ho, and Miranda 2020).

Corruption is also described as a disease that threatens economic improvement, human improvement, and public health improvement. Corruption is very complex which makes it very difficult to overcome. (Mackey et al. 2016). UHC became the main goal and reformed the financing system. UHC policy 
concepts are used to improve public health(Kutzin et al., 2016). In the financing system, in some countries, in practice, they are dealing with the problem of misusing funds in the health system. This action has the potential to misuse health funds as an act of corruption in health financing. The fraud in the health financing system is very much influenced by the condition of the country's income. Health financing in developing countries correlates with a low financing system. (Sirag, Mohamed Nor, and Abdullah 2017)Corruption in health financing occurred both before the COVID pandemic and after the COVID pandemic. During the Covid-19 pandemic, many officers were involved in public health, especially in controlling infectious diseases. This condition has resulted in several countries increasing their budgets to deal with this pandemic and this becomes a new problem if the additional costs are not controlled or are mismanaged. The issue of health workers is an important factor in the health system. Lack of health staff as an indicator of poor health. Universal health coverage (UHC) is difficult to reach. Several countries have a weak system for providing health workers, such as Sierra, Libera, the Democratic Republic of Congo, and Papua New Guinea (Sweeney \& Mulou, 2012). So that innovative solutions are needed to ensure that the country does not fall behind in achieving UHC. (Raven et al., 2020) The increasing health disparities among population groups make the case for the health system even worse. There is a strong correlation between the state and a bad society which also impacts a poor workforce and hinders social and economic development. The health system is very important to create a welfare state. Because a good work system creates good work. (Worku, 2017). The issue of health workers is an important factor in the health system. Lack of health staff as an indicator of poor health. Universal health coverage $(\mathrm{UHC})$ is difficult to reach. Some countries have a weak system for providing health workers such as Sierra, Libera,(Sweeney, and Mulou 2012). So that innovative solutions are needed to ensure that the country does not fall behind in achieving UHC. (Raven et al. 2020)Increasing health disparities among population groups make the case for the health system even worse. There is a strong correlation between the state and a bad society which also impacts a poor workforce and hinders social and economic development. The health system is very important to create a welfare state. Because a good work system creates good work. (Worku 2017)

\section{li. The Problem}

From the background of the above description, the researcher tries to study and analyze how the impact of corruption in the health financing system and how recommendations should be made to protect the community.

\section{lii. Method}

Juridical and descriptive-analytical study methods are used to analyze how acts of corruption can occur and with these two methods, the researcher describes the impact of corruption in the health system, and the prevention analysis with several recommendations is offered as an effort to protect the community.

\section{Iv. Discussion}


Several articles analyzed that health expenditures during a pandemic were still deficient, so a new pattern of thinking was needed in public health expenditures. Public health expenditures, pandemic preparedness facilities, health care resilience can be used together for health resilience. So it needs to be taken seriously. In general, the main source of health financing is taken from direct and indirect taxes in all ASEAN and CHINA countries. Brunei, Indonesia, the Philippines, Malaysia, and Vietnam have one income collection group which is the national health insurance. Cambodia, China, Laos, Singapore, and Thailand implement a double collection system. Myanmar does not have formal regulations. (Myint et al. 2019)We already know that increasing financial protection in the financing system in several countries is experiencing imbalances. Improper payment policies and mechanisms have an impact on the quality of health care provision. To reach UHC you must include vulnerable groups in the health insurance scheme. The higher the percentage of government spending on health the greater the financial protection. (Myint et al. 2019)all health systems struggle to fill the health system with limited resources, especially. lowincome countries. (Witter et al. 2019) in general, the health insurance scheme can be focused on the following issue

The picture above explains that several variables can be used for consideration in making a payment system scheme

\section{a. Health system definition}

Health system financing has the same governance as the mission of the world health organization. A good health system seeks the optimal way to maintain a balance between the delivery and financing of health services with good and appropriate regulations. Proper regulation can be a force to achieve social justice and justice in the health system. The financing system requires clear identification and regulations and regulators to enforce the rules. In general, there are three sub-functions of health financing(Phua, 2018):

From the picture above, everything must be managed properly, however, in practice it often creates problems because the health management system involves larger regulations and transparent financial reports.

\section{b. Impact of corruption}

Corruption in the health sector is very diverse, with its effects hindering progress towards UHC. Corruption does not only impede public access, but also reduce the quality of medicines, and damage protection systems, and financial risks. To deal with corruption in the health sector, it is necessary to identify how this problem occurs. Evidence is used to develop how the crime occurred and the risks(Mackey et al., 2018).

We already know that corruption in the health sector has become a serious problem because it causes financial waste and results in losses in the health sector. However, corruption has become a global plague in both the public and private sectors in both developed and developing countries. The impact of misuse 
of funds, fraud will also threaten future investment so that constant criticism is needed. (Mackey and Liang 2012)Corrupt practices become. In the global problem there are five reasons why the squirrel policy is closed(Hutchinson et al., 2019):

It is undeniable that corruption is an extraordinary crime, dishonesty and fraud have taken root, including in the health sector. Corruption is rarely discussed openly and people are afraid to expose it because it involves public officials and power holders. (García 2019)corruption in the health sector is currently a dirty secret in the health sector so that international development and global activities try to emphasize it because this is a serious problem. After all, it involves human health. (Mackey 2019)

Research finds that many obstacles that cause the system to not run optimally are caused by internal factors and external factors (Dror et al., 2016). The study found that corruption has a negative effect, especially patient care, and the motivation of medical personnel for corruption is also influenced by the lack of mechanisms and checks against corruption and failure to enforce laws(Rispel et al., 2016)

Table 1 Factors inhibiting the implementation of the health system program

\begin{tabular}{|lll|}
\hline Inhibiting Factor & Motivation Factors & Regulation Factor \\
\hline Incompatible benefit package & Knowledge & Strict rules \\
\hline Cultural beliefs & Understanding & Laws and policies are inadequate \\
Range factor & Quality of care & Benefits packages do not match \\
\hline Health facility distance & Trust & \\
Lack of a legal framework & Previous service acceptance & \\
Improper Regulatory Scheme & & \\
\hline Education & & \\
\hline
\end{tabular}

Apart from the above factors, there has also been a delay in receiving health care, including slow processing times and gaps in the number of claims and the amount paid(Panda et al., 2016).

Indonesia is now facing several problems in implementing BPJS health insurance because it has experienced a deficit from 2014-2018(Machmud et al., 2020)

Figure 4 Deficit of the BPJS. Source: Online seminar of the Corruption Eradication Commission (KPK)

From the picture above, there is an indication of moral hazard in the health system. The results showed that several types of moral hazards that have the potential to become corruption cause losses to the state. Although, in practice, law enforcement still experiences obstacles related to significant evidence. 
Several documents mention indicators of types of crime in health financing which can be described in the following table,

Table 2 Data on several types of fraud in health insurance

\begin{tabular}{|llllll|}
\hline \multirow{2}{*}{ No } & Type of Event & \multicolumn{4}{l}{ Number of Cases until July 2016 } \\
\cline { 3 - 5 } & & RJTL & RITL & TOTAL & $\%$ \\
\hline 1 & Upcoding & 230,909 & 297,376 & 528,285 & 49.77 \\
\hline 2 & Service Unbundling or Fragmentation & 259,649 & 5,923 & 265,572 & 25.02 \\
\hline 3 & Readmission & 57,876 & 6,104 & 63,980 & 6.03 \\
\hline 4 & No Medical Value & 34,300 & 10,962 & 45,262 & 4.26 \\
\hline 5 & Type of Room Change & 1,352 & 36,363 & 37,714 & 3.55 \\
\hline 6 & Canceled Services & 31,747 & 3,912 & 35,659 & 3.36 \\
\hline 7 & Standard of Care & 27,305 & 4,708 & 32,013 & 3.02 \\
\hline 8 & Unnecessary Treatment & 15,942 & 4,763 & 20,705 & 1.95 \\
\hline 9 & Repeat Billing & 11,015 & 1,010 & 12,025 & 1.13 \\
\hline 10 & Phantom Procedure & 5,542 & 1,679 & 7,221 & 0.68 \\
\hline 11 & Phantom Billing & 4,890 & 1,215 & 6,105 & 0.58 \\
\hline 12 & Length Of Stay & 663 & 1,603 & 2,266 & 0.21 \\
\hline 13 & Inflated Bills & 1,293 & 554 & 1,847 & 0.17 \\
\hline 14 & Self Referral & 925 & 147 & 1,072 & 0.10 \\
\hline 15 & Cloning & 574 & 226 & 800 & 0.08 \\
\hline 16 & Cost & 347 & 212 & 559 & 0.05 \\
\hline 17 & Excessive use of ventilators & 135 & 196 & 331 & 0.03 \\
\hline Total & & 684,463 & 376,953 & $1,061,416$ & 100.00 \\
\hline & & & & & \\
\hline
\end{tabular}

Looking at table 2 above, it is found that various kinds of potential crime (moral hazard) in the health system. This is very dangerous for patients as recipients of health services resulting in the impact of disease severity and even death. Besides, the longer care system is also a burden on patients and has the potential to become fraud in the health sector. (Machmud et al. 2020) The study found that the appointment of non-medical doctors as internal verifiers, lack of clarity in guidelines for doctors and 
coding, and poor coordination between hospitals and health insurance are the causes of upcoding in the hospital(Syafrawati et al., 2020).

Meanwhile, the five most common corrupt practices that are frequently reported are(Onwujekwe et al., 2019)

The study found that corruption also occurred in Europe, namely a study of corruption in the consumption of antibiotics was found. There is a correlation between corruption, namely the health sector with the public, and the use of antibiotics where the high use of antibiotics also increases the level of the budget(Rönnerstrand \& Lapuente, 2017)research found that in Nigeria there was an increase in deaths 12.7 deaths / 1000 population due to disruption of health services and shortages of drugs due to embezzlement, mismanagement, poor funding, and lack of medical services in public hospitals. This proves that the health sector is very vulnerable to corruption, especially in poor countries. (Ewomazino Akokuwebe, Ewomazino, and Michael 2017; Vian and Crable 2016) opportunities for corruption in the health system occur in (1) governance (2) financing (3) human resources and pharmaceutical management (4) dirty practices (Vian \& Crable, 2016).

\section{Health development model}

An upcoding management policy is needed which must be implemented in the national health insurance program by way of compiling upcoding guidelines, increasing regular medical upcoding training, increasing the number of coders from medical personnel, strengthening regulations for coding as problem-solving in hospitals. (Syafrawati et al., 2020)for example in China, system management has made great progress in creating a health system. By multiplying the rural population, namely the CMS (Cooperative Medical Scheme) or NCMS (New Rural Cooperative Medical) model so that a strong government commitment and combined with administration, clear policy objectives, takes into account local conditions which are all accumulated as a basis for practice. (Swami and Srivastava 2020; Yuan et al. 2017)

The health system in Austria has a high level of health. Life expectancy at births is above the EU average and low mortality are indicators of the EU's good health. The highest mortality rates were due to tobacco and alcohol. Austria's health system provides good service access. Almost all residents receive benefits. Although health is relatively expensive, reforms continue to be carried out to strengthen primary health(Bachner et al., 2018)

In Europe, reforms are continuously pursued to improve health policies, namely in the health system products, consolidation, centralization, and social services. Improving elderly services is also being pursued in the health systems in the Netherlands and Germany. In Canada, the health system is funded by taxes so in general in the European Union health care providers continue to seek health sector funding(Saltman, 2018) 
In Taiwan, several reforms were carried out by implementing the task of a continuous health care institution whose task was to identify and evaluate. The co-payment system must comply with the medical triage system. Where the results show, it must be considered by the leadership so that it is more integrative to improve the quality of better health. (Chang, Wang, and Wang 2018)

America offers contemporary health care policy and federal health care financing policy changes. The United States health care system is considered the most expensive in the world and is certainly ineffective compared to other countries because the increasing cost of health care has made a burden on the underprivileged society because of institutionalized medical practices and technological developments and consumer behavior of each country cannot be equated because of the country. The poor still have difficulties in terms of inadequate infrastructure and lack of medicines. (Dalinjong et al. 2017; Kumar, Ghildayal, and Shah 2011; Sekhri, Feachem, and Ni 2011) America implements a hospital policy that must be led by doctors and specialists. (Tasi et al., 2017) in fifty states in the US, a total of 3608 hospitals are certified Medicare (Fahrenbach et al., 2020). The United States also made a policy about technology maximizing the efficiency of the quality of hospital care. Technology also supports the quality of hospital performance. (Fotovvat 2019; Janakiraman et al. 2018) Technology is also used in designing health information systems in Emergency Units (IGD) called Health Information Exchanges (HIEs) which aim to reduce the length of stay and produce better quality services from doctors and patients. (Janakiraman et al. 2018).

Developed countries try to develop by creating public-private partnerships to harness private financing and expertise to achieve public policy objectives. The partnership went beyond governmental arrangements and was able to combine a new concept of infrastructure with medical services. Partnerships can increase access, quality, and efficiency in health care. (Sekhri, Feachem, and Ni 2011)

Brazil created a program of Maes medicos or more doctors in 2013. This program is aimed at reducing the inequality of emergency doctors. Expansion of medical education in Brazil, the government implements that justice must be considered when determining priorities and allocating resources and considering vulnerable areas as priority areas in a regulation that emphasizes public policy and constitutional rights in the health sector(A. Oliveira et al., 2020; F. P. Oliveira et al., 2015)

For example in Sri Lanka has provided a large part of inpatient care for employees. For 20 years its effectiveness cannot be accounted for. The poor have a higher chance of being burdened by health expenditures. Health schemes are only able to protect $20 \%$ of households.

\section{Recommendation}

Health system improvement is a determining factor for achieving good goals in the health sector, to support this it must be supported by advances in medical technology including financial data related to claims and good service quality. Technology supports cost-effectiveness and prevention and treatment management, so health financing cannot be separated from good financial information to influence policies at all levels. A good system will be integrated into both the private and voluntary public sectors. 
To achieve UHC, the financing system and mechanisms must be regulated effectively through checks and balances, as well as efficiency in administration. (Phua 2018) The UN recommendation model for sustainable development or SDGs as a new approach to anti-corruption governance aims to deal with coordination from all jurisdictions of various countries with a partnership of stakeholders to make anticorruption policies at all levels through the SDGs for human development to be better in the future. (Mackey, Vian, and Kohler 2018).

Several recommendations provide a concept for overcoming corruption so that the problem does not become bigger(Hutchinson et al., 2019):

Given the background that corruption in the health sector is very difficult to reveal, tackling it requires a commitment of academic and research responsibility in all countries, both in developed and developing countries, to make policies, research, and think about efforts for corruption so that development goals are achieved. and ensuring a good life for all, corruption in global health should never be a secret anymore. (García 2019) UK recommendations provide a concept for fighting health corruption by making policy and building an international community in the field of corruption such as the establishment of a global network of anti-corruption, transparency, and accountability (GNACTA) which is recently led by the World Health Organization (WHO), and the building of national unions. -a nation in 2019 to achieve the goals of sustainable development (SDGs) and universal health coverage or (UHC)(Mackey, 2019). The right laws are not sufficient to reduce corruption but there must be the political will to run health services free of corruption. Mechanisms to reduce corruption are as follows (1) political will (2) effective government

enforcing the law (3) proper system (4) community participation (5) advocacy for responsible officials (6) bureaucratic institutions (7) improving human resources and competence (8) proper ethics and value system (8) of equal importance to the goals of the health system(Rispel et al., 2016). The German study made a recommendation that a guideline was needed that prohibited hospital doctors from accepting all forms of benefit from the pharmaceutical industry because doctors could be influenced by the choice of drugs offered by pharmaceutical companies. Supporting this, the study in America also provides recommendations to always evaluate the impact of a law that requires pharmaceutical companies to reward medical personnel because various internal control mechanisms in health centers can stop corruption. (Gaitonde et al. 2016).

\section{Conclusion}

From the overall description above, it can be concluded. The health system of each country has a noble goal of increasing the degree of public health, especially the lower middle class. The health system is very good if it is implemented by the mission and vision of the health system objectives, but in practice, that goal is only good at the theoretical level. There is weakness and vulnerability to corruption because the health system includes various aspects including aspects of financing, finance, and services to the weak community. these conditions create opportunities for corruption. WHO's recommendation can be a reference for implementing all countries to think about public health problems seriously, so that corruption in the health system becomes a serious crime. corruption in the health system can occur in 
various aspects and forms of the mode of crime that is committed, therefore it is necessary to have the right strategy to overcome it. Health corruption perpetrators are dominated by officials who have authority in the health sector, so it is an open secret that corruption crimes in the health sector are difficult to prove, therefore recommendations in various countries conclude in one vision that to prevent, act and sanction. the maximum must be done and a strong political force is needed so that the mission is carried out, namely integrating the Law and the health system must go hand in hand because both will not function optimally if one is damaged.

\section{Declarations}

\section{Availability of data and material}

Some of the data is taken from the references of previous researchers that have been published in the form of journals on Google Scholar that has been indexed in Crossref, Scopus, WoS, etc. The data and materials are quoted from sources from relevant previous studies. Finally, overall, the ideas of most of the authors do not use raw data and new software but are purely the authors' ideas based on empirical experience and analysis of studies from several previous references.

\section{Conflict of interest/competing interest}

The author's idea can be taken and used by anyone who will use it for the benefit of humanity and knowledge sharing and not for the benefit of business competition or profit oriented.

\section{Funding}

This research was purely carried out by the research team itself without any help from anyone or any party.

\section{Author contribution}

That the writing team strongly supports the completion of this research, Erny Herlin as the second researcher with a background in concentration on criminal issues and some empirical experience in this field can certainly be an idea for thinkers and experiences and of course has relevance related to how the concept of development policy in the health sector. The third author who is also relevant to the main author so that many exchange ideas and provide input for the realization of the manuscript. In addition to the team of authors above, the authors would also like to thank all parties who directly or indirectly have helped the realization of this research.

\section{Ethics approval and consent to participate}

Not applicable

\section{Consent for publication}




\section{References}

1. Adedeji, A. S., Doyin, A., Kayode, O. G., \& Ayodele, A. A. (2017). Knowledge, Practice and Willingness to Participate in Community Health Insurance Scheme among Households in Nigerian Capital City. Sudan Journal of Medical Sciences. https://doi.org/10.18502/sjms.v12i1.854

2. Bachner, F., Bobek, J., Habimana, K., Ladurner, J., Lepuschutz, L., Ostermann, H., Rainer, L., Schmidt, A. E., Zuba, M., Quentin, W., \& Winkelmann, J. (2018). Austria: Health System Review. In Health systems in transition.

3. Biggeri, M., Nannini, M., \& Putoto, G. (2018). Assessing the feasibility of community health insurance in Uganda: A mixed-methods exploratory analysis. Social Science and Medicine. https://doi.org/10.1016/j.socscimed.2018.01.027

4. Chang, D. S., Wang, W. S., \& Wang, R. (2018). Identifying Critical Factors of Sustainable Healthcare Institutions' Indicators Under Taiwan's National Health Insurance System. Social Indicators Research. https://doi.org/10.1007/s11205-017-1761-7

5. Chemouni, B. (2018). The political path to universal health coverage: Power, ideas and communitybased health insurance in Rwanda. World Development. https://doi.org/10.1016/j.worlddev.2018.01.023

6. Dalinjong, P. A., Welaga, P., Akazili, J., Kwarteng, A., Bangha, M., Oduro, A., Sankoh, O., \& Goudge, J. (2017). The association between health insurance status and utilization of health services in rural Northern Ghana: Evidence from the introduction of the National Health Insurance Scheme. Journal of Health, Population and Nutrition. https://doi.org/10.1186/s41043-017-0128-7

7. Deliversky, J. (2016). HOW DOES CORRUPTION AFFECTS HEALTHCARE SECTOR IN BULGARIA. Journal of IMAB - Annual Proceeding (Scientific Papers).

https://doi.org/10.5272/jimab.2016221.1088

8. Dror, D. M., Shahed Hossain, S. A., Majumdar, A., Koehlmoos, T. L. P., John, D., \& Panda, P. K. (2016). What factors affect voluntary uptake of community-based health insurance schemes in low-and middle-income countries? A systematic review and meta-analysis. In PLOS ONE. https://doi.org/10.1371/journal.pone.0160479

9. Ewomazino Akokuwebe, M., Ewomazino, M., \& Michael, D. (2017). Corruption in the Health Sector and Implications for Service Delivery in Oyo State Public Hospitals. In Ilorin Journal of Sociology.

10. Fahrenbach, J., Chin, M. H., Huang, E. S., Springman, M. K., Weber, S. G., \& Tung, E. L. (2020). Neighborhood Disadvantage and Hospital Quality Ratings in the Medicare Hospital Compare Program. Medical Care. https://doi.org/10.1097/MLR.0000000000001283

11. Fotovvat, H. (2019). Predictors of Hospital Quality and Efficiency.

12. Gaitonde, R., Oxman, A. D., Okebukola, P. O., \& Rada, G. (2016). Interventions to reduce corruption in the health sector. In Cochrane Database of Systematic Reviews. 
https://doi.org/10.1002/14651858.CD008856.pub2

13. García, P. J. (2019). Corruption in global health: the open secret. In The Lancet. https://doi.org/10.1016/S0140-6736(19)32527-9

14. Hutchinson, E., Balabanova, D., \& McKee, M. (2019). We need to talk about corruption in health systems. In International Journal of Health Policy and Management.

https://doi.org/10.15171/IJHPM.2018.123

15. Janakiraman, R., Park, E., Demirezen, E., \& Kumar, S. (2018). The Effects of Health Information Exchange Access on Healthcare Quality and Efficiency: An Empirical Investigation. SSRN Electronic Journal. https://doi.org/10.2139/ssrn.2915190

16. Kumar, S., Ghildayal, N. S., \& Shah, R. N. (2011). Examining quality and efficiency of the US healthcare system. In International Journal of Health Care Quality Assurance. https://doi.org/10.1108/09526861111139197

17. Kutzin, J., Yip, W., \& Cashin, C. (2016). Alternative Financing Strategies for Universal Health Coverage. https://doi.org/10.1142/9789813140493_0005

18. Lu, H. S., Ho, B. X., \& Miranda, J. J. (2020). Corruption in health systems: The conversation has started, now time to continue it: Comment on "We need to talk about corruption in health systems." International Journal of Health Policy and Management. https://doi.org/10.15171/ijhpm.2019.104

19. Machmud, R., Syafrawati, S., Aljunid, S. M., \& Semiarty, R. (2020). DOES MORAL HAZARD OCCOUR IN THE IMPLEMENTATION OF SOCIAL HEALTH INSURANCE? EVIDENCE FROM PUBLIC HOSPITALS IN A RURAL PROVINCE OF INDONESIA. Asia Pacific Fraud Journal, 5(1), 24-32.

20. Mackey, T. K. (2019). Opening the policy window to mobilize action against corruption in the health sector: Comment on "We need to talk about corruption in health systems." In International Journal of Health Policy and Management. https://doi.org/10.15171/ijhpm.2019.65

21. Mackey, T. K., Kohler, J. C., Savedoff, W. D., Vogl, F., Lewis, M., Sale, J., Michaud, J., \& Vian, T. (2016). The disease of corruption: Views on how to fight corruption to advance 21 st century global health goals. BMC Medicine. https://doi.org/10.1186/s12916-016-0696-1

22. MacKey, T. K., \& Liang, B. A. (2012). Combating healthcare corruption and fraud with improved global health governance. BMC International Health and Human Rights. https://doi.org/10.1186/1472$698 X-12-23$

23. Mackey, T. K., Vian, T., \& Kohler, J. (2018). The sustainable development goals as a framework to combat health-sector corruption. Bulletin of the World Health Organization. https://doi.org/10.2471/BLT.18.209502

24. Meessen, B. (2018). The role of digital strategies in financing health care for universal health coverage in low- and middle-income countries. Global Health Science and Practice. https://doi.org/10.9745/GHSP-D-18-00271

25. Myint, C. Y., Pavlova, M., Thein, K. N. N., \& Groot, W. (2019). A systematic review of the healthfinancing mechanisms in the association of southeast asian nations countries and the people's 
Republic of China: Lessons for the move towards universal health coverage. In PLOS ONE. https://doi.org/10.1371/journal.pone.0217278

26. Oliveira, A., Barreto, J. O. M., de Araújo, S. Q., \& Santos, L. M. P. (2020). Spatial distribution of the "Mais Médicos (More Doctors) Program" and social vulnerability: an analysis of the Brazilian metropolitan regions. Human Resources for Health, 18(1), 1-11.

27. Oliveira, F. P., Vanni, T., Pinto, H. A., Santos, J. T. R., Figueiredo, A. M., \& Araujo, S. Q. (2015). Mais Médicos: um programa brasileiro em uma perspectiva internacional. Interface - Comun Saúde Educ, 19. https://doi.org/10.1590/1807-57622014.1142

28. Onwujekwe, O., Agwu, P., Orjiakor, C., McKee, M., Hutchinson, E., Mbachu, C., Odii, A., Ogbozor, P., Obi, U., Ichoku, H., \& Balabanova, D. (2019). Corruption in Anglophone West Africa health systems: A systematic review of its different variants and the factors that sustain them. In Health Policy and Planning. https://doi.org/10.1093/heapol/czz070

29. Panda, P., Chakraborty, A., Raza, W., \& Bedi, A. S. (2016). Renewing membership in three communitybased health insurance schemes in rural India. Health Policy and Planning. https://doi.org/10.1093/heapol/czw090

30. Phua, K. H. (2018). Governance Issues in Health Financing $\otimes$. In Reference Module in Biomedical Sciences. https://doi.org/10.1016/b978-0-12-801238-3.66207-4

31. Raven, J., Wurie, H., Idriss, A., Bah, A. J., Baba, A., Nallo, G., Kollie, K. K., Dean, L., Steege, R., \& Martineau, T. (2020). How should community health workers in fragile contexts be supported: Qualitative evidence from Sierra Leone, Liberia and Democratic Republic of Congo.

32. Rispel, L. C., Jager, P. De, \& Fonn, S. (2016). Exploring corruption in the South African health sector. Health Policy and Planning. https://doi.org/10.1093/heapol/czv047

33. Rönnerstrand, B., \& Lapuente, V. (2017). Corruption and use of antibiotics in regions of Europe. Health Policy. https://doi.org/10.1016/j.healthpol.2016.12.010

34. Saltman, R. B. (2018). The impact of slow economic growth on health sector reform: A cross-national perspective. Health Economics, Policy and Law. https://doi.org/10.1017/S1744133117000445

35. Sekhri, N., Feachem, R., \& Ni, A. (2011). Public-private integrated partnerships demonstrate the potential to improve health care access, quality, and efficiency. Health Affairs. https://doi.org/10.1377/hlthaff.2010.0461

36. Sirag, A., Mohamed Nor, N., \& Abdullah, N. M. R. (2017). Health financing: Does governance quality matter? Iranian Economic Review. https://doi.org/10.22059/ier.2017.62946

37. Swami, S., \& Srivastava, T. (2020). Role of Culture, Values, and Politics in the Implementation of Health Technology Assessment in India: A Commentary. In Value in Health. https://doi.org/10.1016/j.jval.2019.10.002

38. Sweeney, R., \& Mulou, N. (2012). Fee or free? Trading equity for quality of care for primary health care in Papua New Guinea. International Health. https://doi.org/10.1016/j.inhe.2012.07.003

39. Syafrawati, S., Machmud, R., Aljunid, S. M., \& Semiarty, R. (2020). INCIDENCE AND ROOT CAUSE OF UPCODING IN THE IMPLEMENTATION OF SOCIAL HEALTH INSURANCE IN RURAL PROVINCE 
HOSPITAL IN INDONESIA. Asia Pacific Fraud Journal, 5(1), 56-61.

40. Tasi, M. C., Keswani, A., \& Bozic, K. J. (2017). Does physician leadership affect hospital quality, operational efficiency, and financial performance? Health Care Management Review. https://doi.org/10.1097/HMR.0000000000000173

41. Tshitangano, T. G., \& Olaniyi, F. C. (2018). Sustaining the National Health Insurance Scheme in South Africa: The Roles and Challenges of Community Health Workers. The Open Public Health Journal. https://doi.org/10.2174/1874944501811010494

42. Vian, T., \& Crable, E. L. (2016). Corruption and the Consequences for Public Health. In International Encyclopedia of Public Health. https://doi.org/10.1016/B978-0-12-803678-5.00091-6

43. Witter, S., Anderson, I., Annear, P., Awosusi, A., Bhandari, N. N., Brikci, N., Binachon, B., Chanturidze, T., Gilbert, K., Jensen, C., Lievens, T., McPake, B., Raichowdhury, S., \& Jones, A. (2019). What, why and how do health systems learn from one another? Insights from eight low- and middle-income country case studies. Health Research Policy and Systems. https://doi.org/10.1186/s12961-018-0410-1

44. Worku, E. B. (2017). Research for Health Priorities in the Northern Cape Province: Fostering Research Capacity to Translate the Identified Research Needs into Action. American Journal of Public Health Research. https://doi.org/10.12691/ajphr-5-1-5

45. Yuan, B., Jian, W., He, L., Wang, B., \& Balabanova, D. (2017). The role of health system governance in strengthening the rural health insurance system in China. In International Journal for Equity in Health. https://doi.org/10.1186/s12939-017-0542-x

\section{Figures}

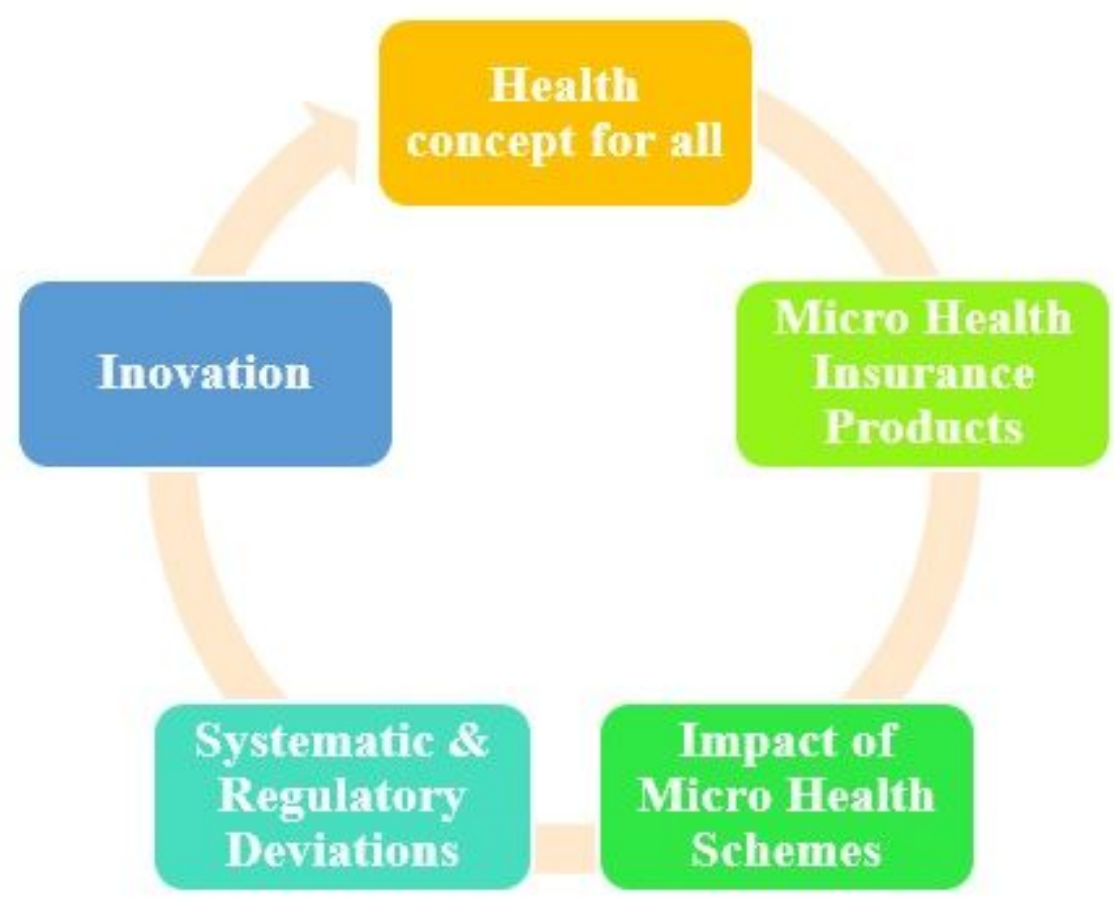


Figure 1

Variables in determining the health financing scheme

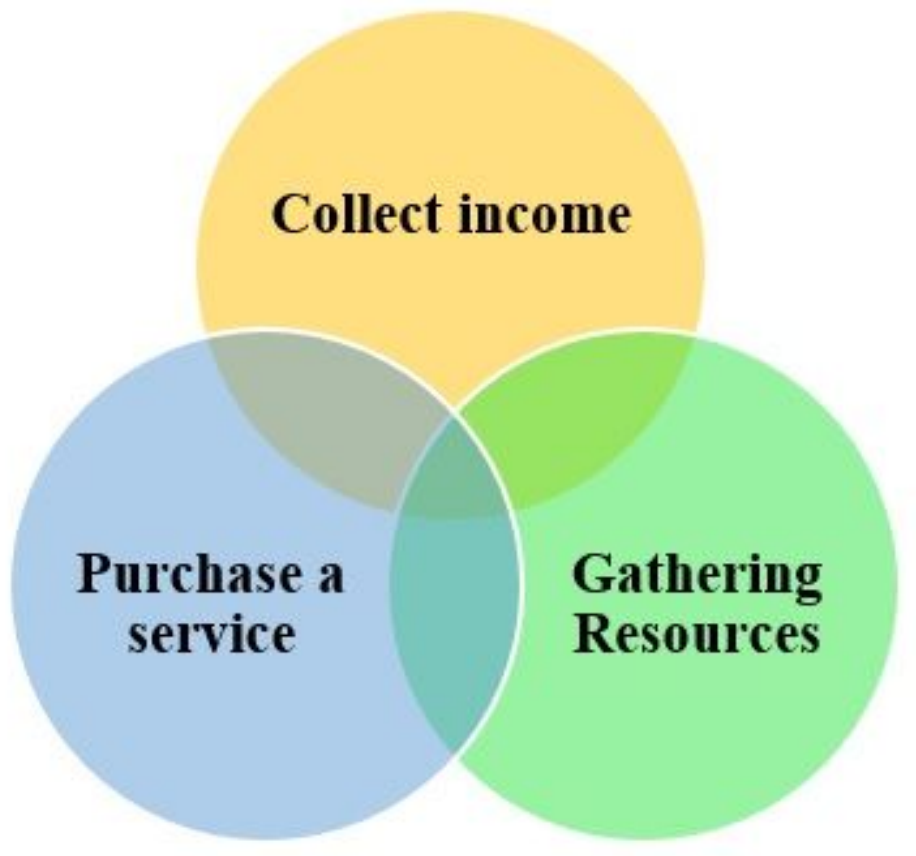

Figure 2

Sub-function of health financing
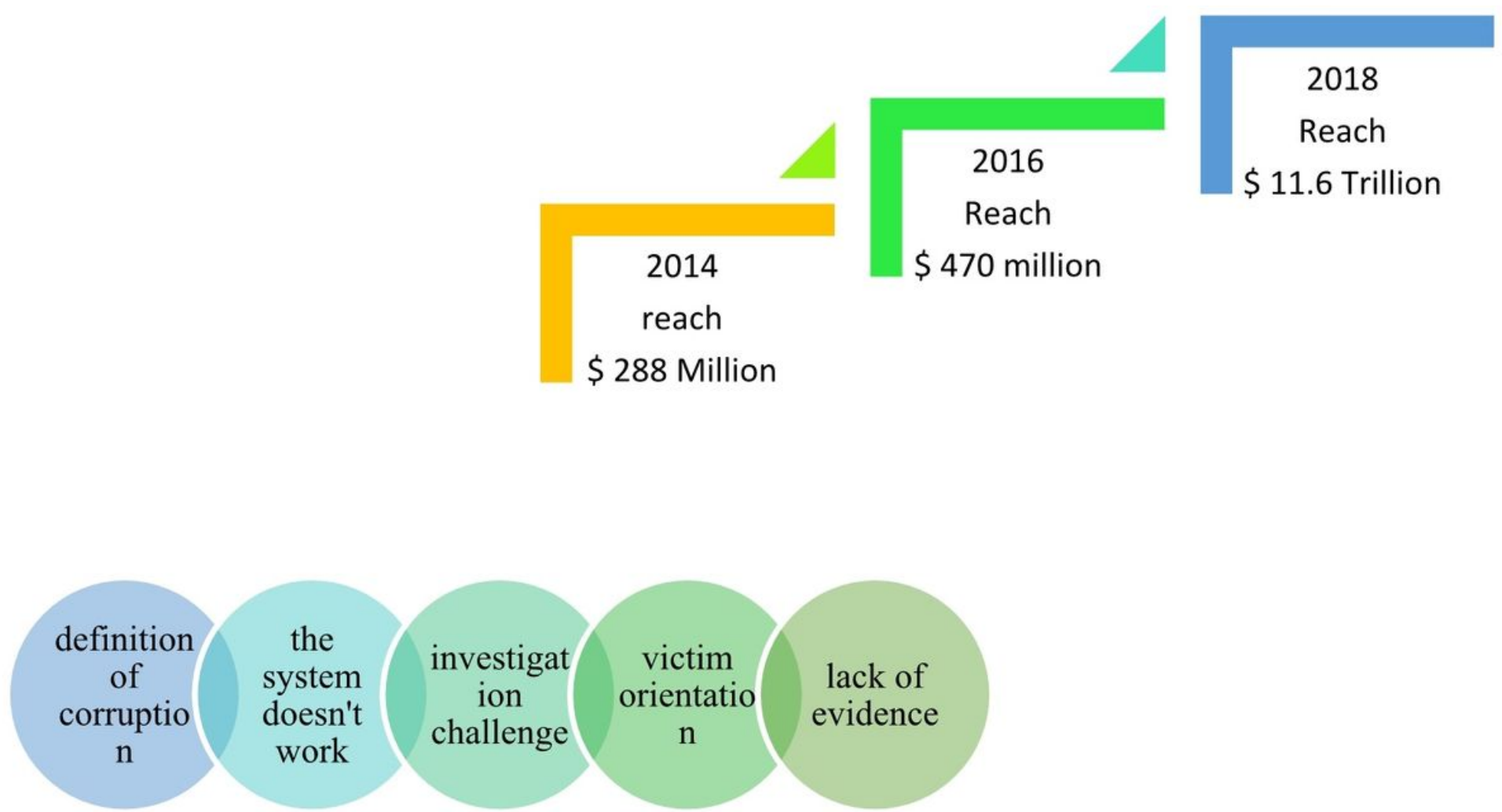
Figure 3

The problem of corruption as a closed crime

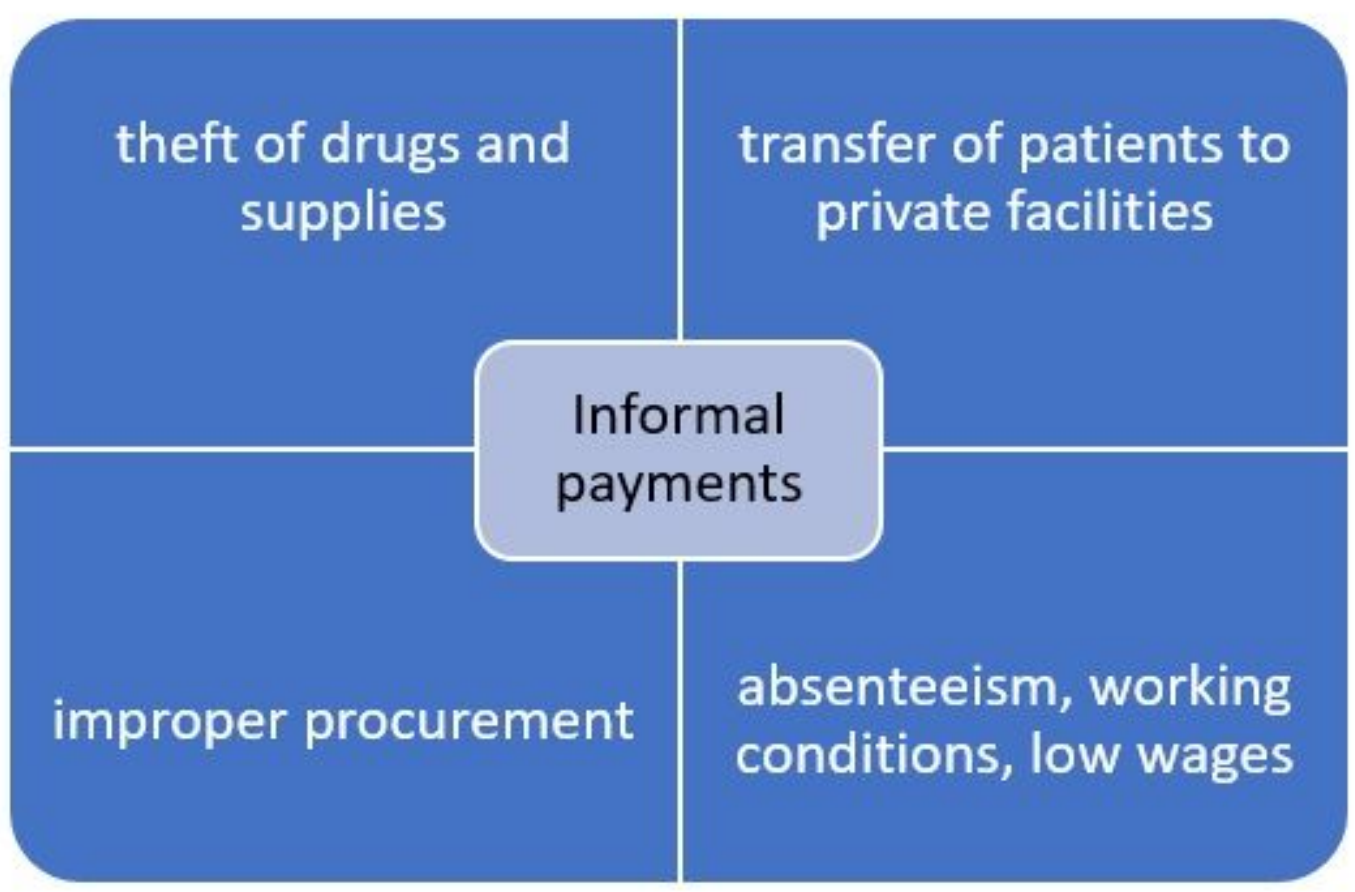

Figure 4

general study of corrupt practices 


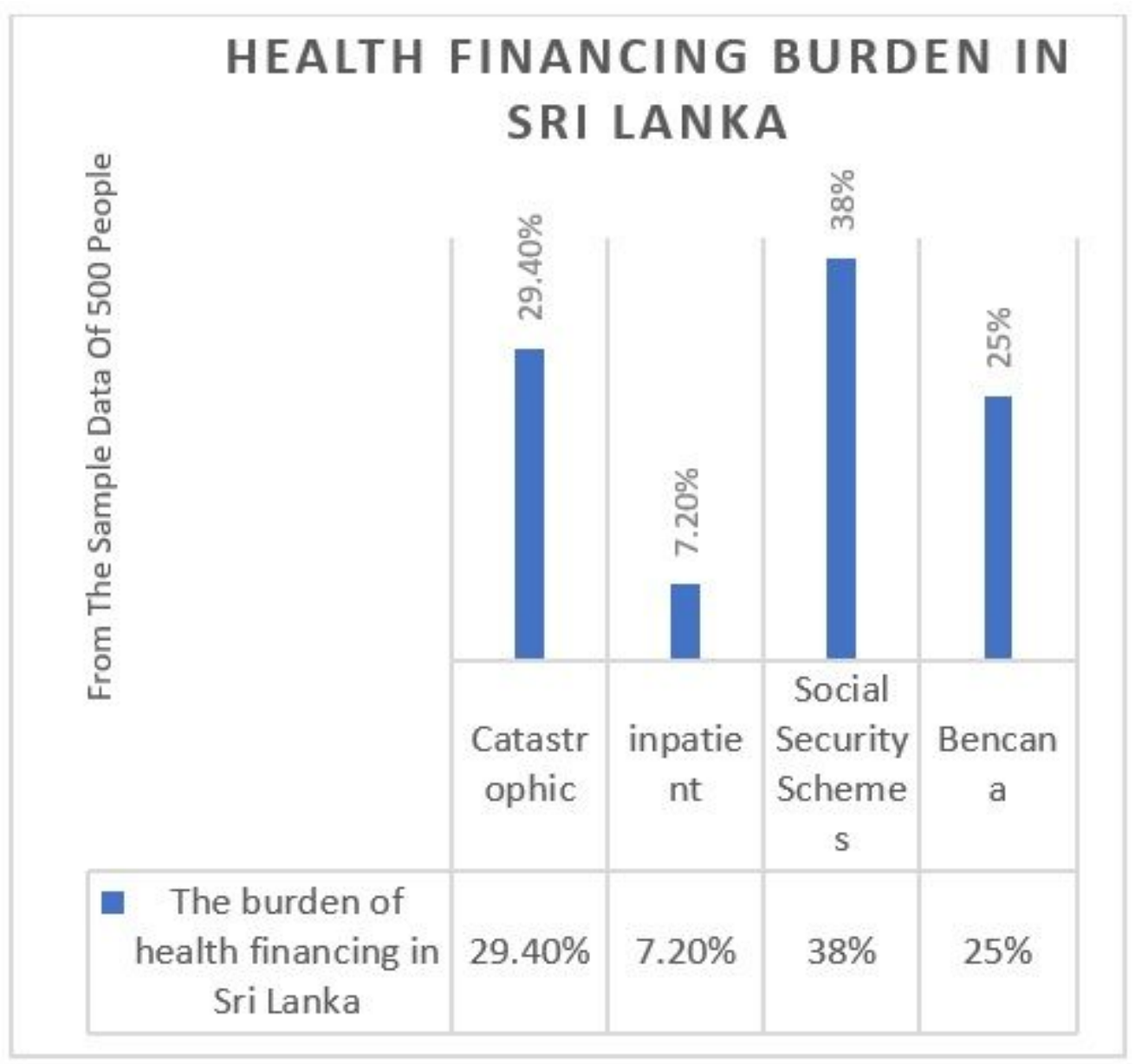

Figure 5

examples of health financing budget in Sri Lanka 